\title{
Curcumin-coordinated nanoparticles with improved stability for reactive oxygen species- responsive drug delivery in lung cancer therapy
}

This article was published in the following Dove Press journal:

International Journal of Nanomedicine

25 January 2017

Number of times this article has been viewed

\author{
Cheng-Qiong Luo ${ }^{1-3, *}$ \\ Lei Xing ${ }^{1-3, *}$ \\ Peng-Fei Cui' \\ Jian-Bin Qiao' \\ Yu-jing $\mathrm{He}^{\prime}$ \\ Bao-An Chen ${ }^{4}$ \\ Liang Jin ${ }^{1,2,5}$ \\ Hu-Lin Jiang ${ }^{1-3}$
}

'State Key Laboratory of Natural Medicines, Department of Pharmaceutics, ${ }^{2}$ Jiangsu Key Laboratory of Drug Screening, 3 Jiangsu Key Laboratory of Drug Discovery for Metabolic Diseases, China Pharmaceutical University, ${ }^{4}$ Department of Hematology, The Affiliated Zhongda Hospital of Southeast University, ${ }^{5} \mathrm{School}$ of Life Science and Technology, China Pharmaceutical University, Nanjing, China

*These authors contributed equally to this work

Correspondence: Hu-Lin Jiang State Key Laboratory of Natural Medicines, Department of Pharmaceutics, China Pharmaceutical University, Tongjia Xiang 24, Nanjing 210009, China Tel/fax +86 $258327 \quad 027$

Email jianghulin3@163.com

Liang Jin

School of Life Science and Technology,

China Pharmaceutical University, Tongjia

Xiang 24, Nanjing 210009, China

Tel/fax +86 258327 I242

Email liangjin1975@cpu.edu.cn
Background: The natural compound curcumin (Cur) can regulate growth inhibition and apoptosis in various cancer cell lines, although its clinical applications are restricted by extreme water insolubility and instability. To overcome these hurdles, we fabricated a Cur-coordinated reactive oxygen species (ROS)-responsive nanoparticle using the interaction between boronic acid and Cur.

Materials and methods: We synthesized a highly biocompatible 4-(hydroxymethyl) phenylboronic acid (HPBA)-modified poly(ethylene glycol) (PEG)-grafted poly(acrylic acid) polymer $(\mathrm{PPH})$ and fabricated a Cur-coordinated ROS-responsive nanoparticle (denoted by PPHC) based on the interaction between boronic acid and Cur. The mean diameter of the Cur-coordinated PPHC nanoparticle was $163.8 \mathrm{~nm}$ and its zeta potential was $-0.31 \mathrm{mV}$. The Cur-coordinated PPHC nanoparticle improved Cur stability in physiological environment and could timely release Cur in response to hydrogen peroxide $\left(\mathrm{H}_{2} \mathrm{O}_{2}\right)$. PPHC nanoparticles demonstrated potent antiproliferative effect in vitro in A549 cancer cells. Furthermore, the viability of cells treated with PPHC nanoparticles was significantly increased in the presence of $N$-acetylcysteine (NAC), which blocks Cur release through ROS inhibition. Simultaneously, the ROS level measured in A549 cells after incubation with PPHC nanoparticles exhibited an obvious downregulation, which further proved that ROS depression indeed influenced the therapeutic effect of Cur in PPHC nanoparticles. Moreover, pretreatment with phosphate-buffered saline (PBS) significantly impaired the cytotoxic effect of Cur in A549 cells in vitro while causing less damage to the activity of Cur in PPHC nanoparticle.

Conclusion: The Cur-coordinated nanoparticles developed in this study improved Cur stability, which could further release Cur in a ROS-dependent manner in cancer cells.

Keywords: coordination, curcumin, phenylboronic acid, stimuli-responsive, hydrogen peroxide

\section{Introduction}

Curcumin (Cur) is a hydrophobic phenol and derived from the rhizome of Curcuma longa.${ }^{1}$ Cur has gained immense attention for its various therapeutic properties, such as antioxidant, ${ }^{2}$ anti-inflammatory, ${ }^{3}$ and anticancer activities. ${ }^{4}$ Among these properties, its inhibitory effect on cancer via several biological pathways that are involved in apoptosis, tumor proliferation, and metastases has been widely studied. ${ }^{5,6}$ For example, Yang et $\mathrm{al}^{7}$ demonstrated that Cur induced the apoptosis of small cell lung cancer via reactive oxygen species (ROS) signaling pathway. However, poor aqueous solubility and extreme instability at physiological environment of Cur result in attenuated adsorption and fast elimination, which impede its therapeutic use. ${ }^{8}$ These unfavorable properties 
have brought intensive research interest in improving the bioavailability of Cur. During the past decades, numerous approaches have been developed to overcome the limitations described earlier, ${ }^{9-11}$ and nanomedicine formulations tend to be promising candidates for efficient Cur delivery. For example, Phan et al $^{12}$ reported that a Cur-loaded polylactic acid-poly(ethylene glycol) (PLA-PEG) micellar nanosystem could significantly improve Cur's solubility, and a Cur polymer constructed by Tang et $\mathrm{al}^{13}$ exhibited both good solubility and stability. However, there is still an urgent need to develop intelligent delivery systems to transport Cur with superior aqueous solubility and stability.

Stimuli-responsive delivery system with tailored release profiles has received tremendous attention. ${ }^{14}$ In comparison to conventional nanocarriers, these "smart" nanovehicles have demonstrated great potential to overcome problems such as instability and premature release of drugs at physiological environment ${ }^{14,15}$ and have revealed prominent in vitro and in vivo antitumor efficiency. Endogenous stimuli, such as low interstitial $\mathrm{pH}$, high glutathione concentration, and overexpressed ROS level, are often utilized as internal triggers for drug release at target sites. ${ }^{15}$ Among them, ROS, including $\mathrm{H}_{2} \mathrm{O}_{2}, \mathrm{O}_{2}$ (superoxide), $\mathrm{OH}$ (hydroxyl radical), $\mathrm{OCl}$ (hypochlorite ion), $\mathrm{NO}$ (nitric oxide), $\mathrm{ONOO}^{-}$, and $\mathrm{NO}_{2}^{-}$ (peroxynitrite), are important regulators of various signaling pathways at physiological level, while increased ROS levels may contribute to oxidative stress and lead to irreversible damage to cells. ${ }^{16,17}$ It is well recognized that ROS is usually elevated in various tumors, ${ }^{18,19}$ and numerous stimuliresponsive delivery systems containing ROS-responsive groups, such as aryl boronic ester, ferrocenyl, selenium, and thioether groups, have been constructed for excellent controlled-release of drugs. ${ }^{20}$ For instance, Li et al ${ }^{21}$ have conjugated a nitrogen mustard onto a polymer via a cyclic boronate ester group and the polymeric nanoparticles have shown $\mathrm{H}_{2} \mathrm{O}_{2}$-induced DNA alkylation as well as enhancement of cell inhibition efficiency in A549 cells.

Inspired by the ROS-responsive characteristic of boronic acid and its ability to coordinate with Cur, in this study, we intend to fabricate a ROS-responsive polymeric nanoparticle to conquer the insolubility and instability issues faced with Cur delivery and look forward to achieve on demand rapid drug release in ROS-elevated cancer cells. As illustrated in Figure 1, 4-(hydroxymethyl) phenylboronic acid (HPBA)-modified PEG-grafted poly(acrylic acid) polymer (PPH) was first synthesized and then complexed with Cur to form curcumin-coordinated ROS-responsive nanoparticle (denoted by PPHC) through coordination interaction between Cur and boronic acid. The PPHC nanoparticles with improved Cur solubility and stability were supposed to localize at the tumor site via enhanced permeation and retention (EPR) effect and release Cur in response to ROS after cellular endocytosis, which then resulted in apoptosis. The physicochemical characteristics of PPHC, the interaction between boronic acid and Cur, stability assay of Cur, therapeutic effects, and mechanisms were investigated in detail.

\section{Materials and methods Materials}

Methoxy poly(ethylene glycol) amine (mPEG-NH ${ }_{2}, \mathrm{Mw}$ $5 \mathrm{kDa}$ ) was obtained from Xiamen Sinopeg Biotech Co., Ltd. (Xiamen, China). HPBA and 1-(3-dimethylaminopropyl)3-ethylcarbodiimide (EDC) were purchased from Energy Chemical Co., Ltd. (Shanghai, China). $N$-Hydroxysuccinimide (NHS) and Curcumin (Cur) were purchased from Aladdin Industries Inc. (Shanghai, China). Poly(acrylic acid) (PAA, Mw $5 \mathrm{kDa}$ ) and 4-dimethylaminopyridine (DMAP) were obtained from J\&K Scientific Ltd. (Beijing, China). RPMI 1640, 3-(4,5-dimethylthiazol-2-yl)-2,5-diphenyltetrazolium bromide (MTT), and Hoechst 33342 were purchased from KeyGENBioTECH (Nanjing, China). LysoTracker $^{\circledR}$ Red DND-99 and fetal bovine serum (FBS) were purchased from Thermo Fisher Scientific (Waltham, MA, USA). $N$-acetyl-cysteine (NAC) was purchased from Tianjin Heowns Biochemical Technology Co., Ltd. (Tianjin, China). All other chemicals and reagents were obtained from commercial sources with the highest purity available. A549 cells were purchased from cell storeroom of Chinese Academy of Sciences (Shanghai, China).

\section{Synthesis of boronic acid-modified mPEG-PAA}

Poly(ethylene glycol)-grafted poly(acrylic acid) polymer (PP) was synthesized according to the method described in our previous study. ${ }^{22}$ Briefly, PAA ( $200 \mathrm{mg}, 0.04 \mathrm{mmol}$ ) was dissolved in $15 \mathrm{~mL}$ distilled water and activated in the presence of EDC (17 mg, $0.08 \mathrm{mmol}$ ) and NHS (9 mg, $0.08 \mathrm{mmol})$. After stirring for $2 \mathrm{~h}$ at room temperature, $\mathrm{mPEG}-\mathrm{NH}_{2}$ was added and the mixture was allowed to react for $24 \mathrm{~h}$ followed by dialysis (molecular weight cut-off $(\mathrm{MWCO})=5,000 \mathrm{Da})$ against distilled water for $72 \mathrm{~h}$. After lyophilization, the composition of resultant product was characterized by ${ }^{1} \mathrm{H}$ nuclear magnetic resonance spectroscopy ( ${ }^{1} \mathrm{H}$ NMR).

PPH was synthesized via an ester reaction between the hydroxyl group of HPBA and carboxyl group of PP. In brief, PP in DMSO was activated by EDC followed by the addition of DMAP and HPBA (molar ratio: -COOH:EDC: NHS:HPBA $=1: 0.6: 0.6: 2$ ). The reaction was performed 


\section{A}

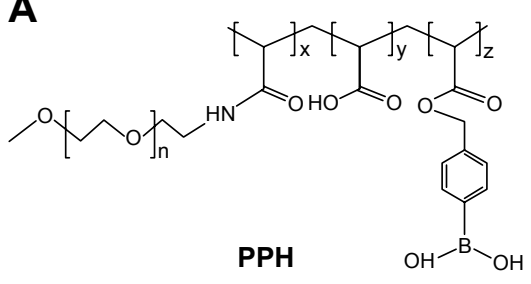<smiles>COc1cc(/C=C/CC(O)CC(=O)/C=C/c2ccc(O)c(OC)c2)ccc1O</smiles>
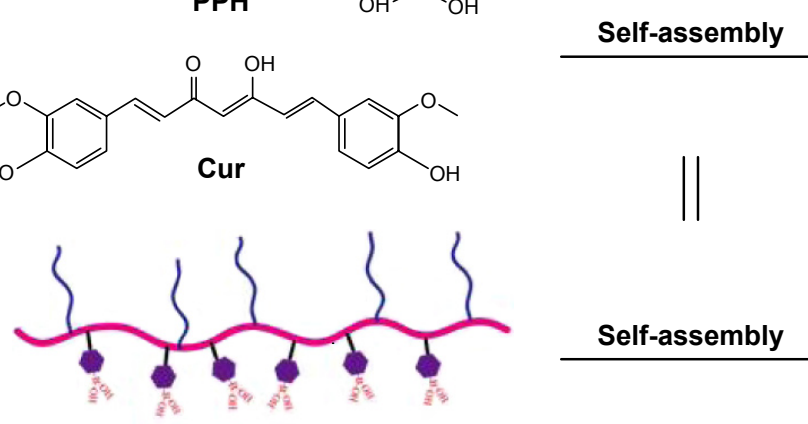<smiles>C=C</smiles>

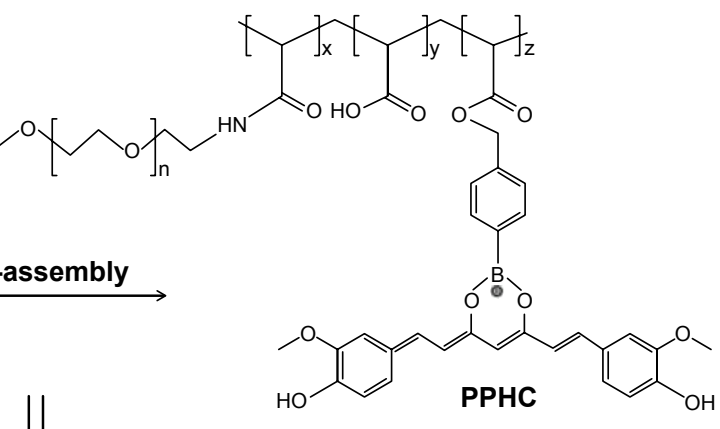

Self-assembly

$\because 0$
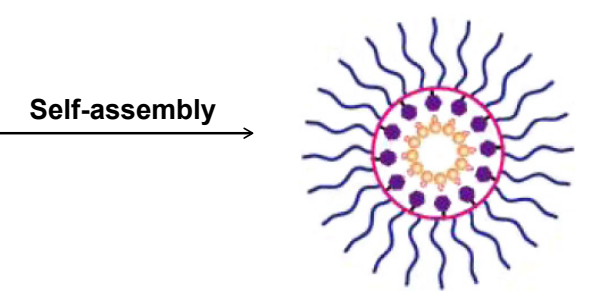

$\sim$ PAA $\bigcirc$ PEG $\bigcirc$ Cur

B

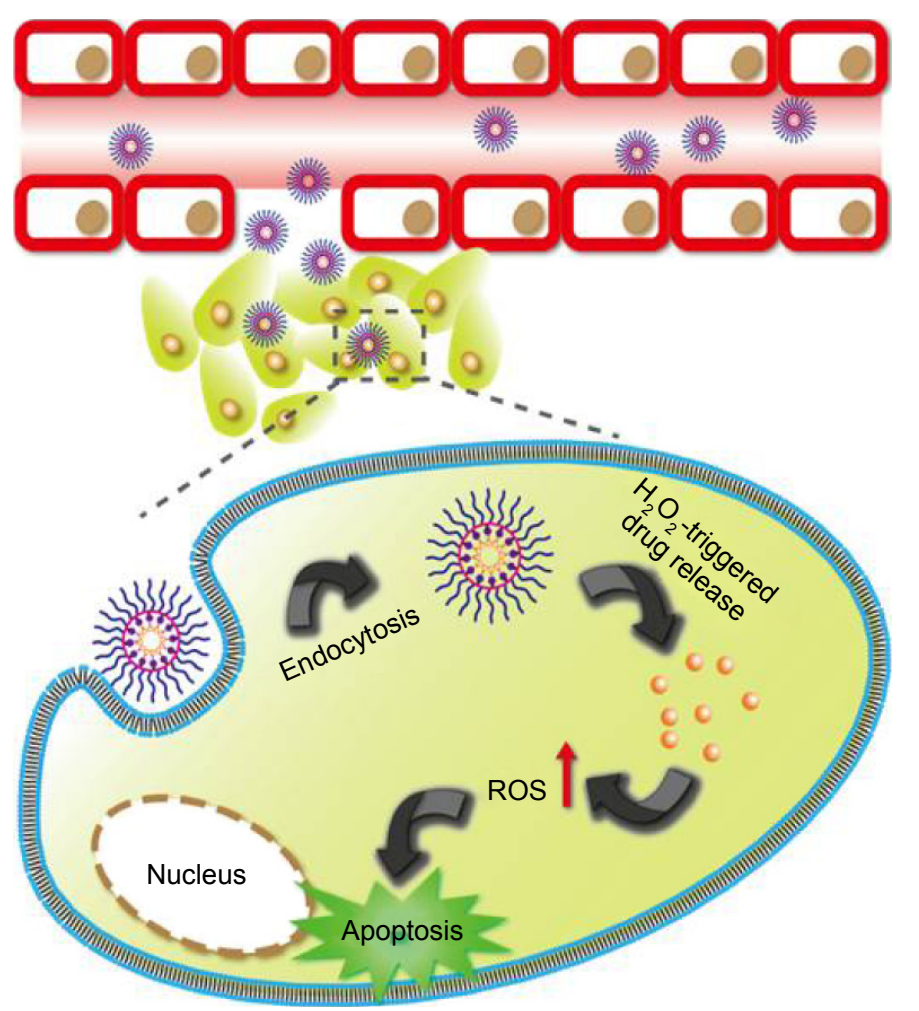

Figure I Schematic illustration of the preparation and intracellular delivery process of ROS-sensitive PPHC nanoparticles.

Notes: (A) Illustration on the preparation of ROS-responsive PPHC nanoparticles using the coordination effect between boronic acid and Cur. (B) Schematic presentation of intracellular ROS-triggered drug delivery and cell apoptosis induced by amplified ROS signals.

Abbreviations: ROS, reactive oxygen species; PPH, 4-(hydroxymethyl) phenylboronic acid-modified PEG-grafted poly (acrylic acid) polymer; PPHC, curcumin-coordinated ROS-responsive nanoparticle; Cur, curcumin; PAA, poly(acrylic acid); HPBA, 4-(hydroxymethyl) phenylboronic acid; $\mathrm{PEG}$, poly(ethylene glycol); $\mathrm{H}_{2} \mathrm{O}_{2}$, hydrogen peroxide.

under the ambient temperature for $24 \mathrm{~h}$ and dialyzed ( $\mathrm{MWCO}=5,000 \mathrm{Da}$ ) against DMSO to remove unreacted reagents for $48 \mathrm{~h}$ followed by distilled water for $48 \mathrm{~h}$. After lyophilization, the structure of synthesized polymer was confirmed by ${ }^{1} \mathrm{H}$ NMR spectroscopy, and HPBA-grafting degree of PPH was calculated according to calibration curve of HPBA in DMSO established via UV-Vis spectrophotometer (Multikan GO, Thermo Fisher Scientific). 


\section{Fabrication of PPHC nanoparticles}

According to previously reported method, ${ }^{23}$ methanol was necessary for boronic acid to coordinate with Cur; therefore, the complexes in this work were prepared in the presence of methanol. In short, Cur $(5 \mathrm{mg} / \mathrm{mL}$ in methanol) was mixed with PPH (20 mg/mL in DMSO) and stirred for $4 \mathrm{~h}$ to ensure that Cur form tight complexes with free boronic acid-containing polymer (Cur:PPH $=18: 100, w / w)$. Then the mixture was added dropwise into distilled water and stirred for another $6 \mathrm{~h}$. After dialysis ( $\mathrm{MWCO}=3,500 \mathrm{Da}$ ) against distilled water for $24 \mathrm{~h}$ to remove organic solvent, the mixture was centrifuged at 3,000 rpm for $10 \mathrm{~min}$ to remove any precipitates. ${ }^{24}$ The obtained sample was stocked in $4^{\circ} \mathrm{C}$ for further use.

To estimate the amount of Cur in the nanoparticles, the nanoparticles were destroyed with ethanol and then the content of Cur was measured according to the calibration curve of Cur in ethanol established via UV-Vis spectrophotometer with the detection wavelength at $426 \mathrm{~nm} .{ }^{25}$ The percentages of drug loading (DL\%) and encapsulation efficiency (EE\%) were calculated using the following equations:

$$
\begin{aligned}
& \mathrm{DL} \%=\frac{\text { Weight of drug in nanoparticles }}{\text { Weight of drug and polymer }} \times 100 \\
& \mathrm{EE} \%=\frac{\text { Weight of drug in nanoparticles }}{\text { Weight of free drug }} \times 100
\end{aligned}
$$

To determine the coordination interaction between Cur and boronic acid, which plays an important role in the formation of PPHC nanoparticles, the color differences between PPHC, PPH, and mixture of Cur and PP were monitored. Also, Cur monomer, HPBA, and the mixture of Cur and HPBA in solvent (DMSO- $\mathrm{d}_{6}$ :deuteromethanol $=1: 1$ ) were characterized by ${ }^{1} \mathrm{H}$ NMR spectroscopy. Simultaneously, the UV-Vis spectra and fluorescence spectra of the nanoparticle and Cur were also measured.

\section{Physicochemical characterization of the PPHC nanoparticles}

The particle size and zeta potential of the nanoparticles were determined by dynamic light scattering (DLS) and zeta potential analyzer (Brookhaven Instruments, Holtsville, NY, USA). The morphology of nanoparticle was examined by transmission electron microscopy ([TEM], JEM-200 CX; JEOL, Tokyo, Japan). The nanoparticle solution was dropped onto carbon-coated copper grids, after 5-min drying at room temperature, the image was observed by TEM.
For stability investigation, the nanoparticle stock solution was diluted by phosphate-buffered saline (PBS $50 \mathrm{mM}$, $\mathrm{pH}=7.4$ ), RPMI 1640 containing $10 \% \mathrm{FBS}$, and $\mathrm{H}_{2} \mathrm{O}_{2}$ aqueous solution $(2 \mathrm{mM})$. Size fluctuations in these media were measured by DLS at specified time intervals.

For further verification of Cur stability in PPHC nanoparticles, the PPHC nanoparticles were diluted with PBS with the Cur concentration kept at $20 \mu \mathrm{g} / \mathrm{mL}$. Cur was dissolved in 5\% DMSO-PBS considering the poor water solubility of Cur in water $\left(11 \mu \mathrm{g} / \mathrm{mL}^{26}\right)$. The absorbance of Cur alone and PPHC nanoparticles in PBS was then recorded by UV-Vis spectrophotometer.

\section{In vitro $\mathrm{H}_{2} \mathrm{O}_{2}$-triggered Cur release from the PPHC nanoparticle}

In vitro release of Cur $(35 \mu \mathrm{g} / \mathrm{mL})$ was conducted by incubating PPHC with $2 \mathrm{mM} \mathrm{H}_{2} \mathrm{O}_{2}$ (twofold to the molar ratio of HPBA in the polymer). ${ }^{27}$ The color change of the nanoparticle with or without $\mathrm{H}_{2} \mathrm{O}_{2}$ at different time intervals was photographed for comparison. In addition, both the aqueous solution were centrifuged at 3,000 rpm for $3 \mathrm{~min}$ and photographed after $4 \mathrm{~h}$ incubation. Furthermore, full-wavelength scanning of both solutions was also recorded by UV-Vis spectrophotometer.

\section{In vitro cell viability assay}

Cytotoxicity effect was evaluated on A549 cells. The A549 cells were seeded on a 96-well plate in RPMI 1640 medium supplemented with $10 \%$ FBS at the initial density of $1 \times 10^{4}$ per well and allowed to grow overnight to reach $80 \%$ confluence. After removing the medium, the FBS-free RPMI 1640 medium containing various doses of PPH, Cur, and PPHC nanoparticles was loaded to designated wells. The groups untreated or treated with $0.5 \%$ DMSO were used as negative controls. After 24 or $72 \mathrm{~h}$ incubation, $20 \mu \mathrm{L}$ MTT reagent was added. After another $4 \mathrm{~h}$ incubation at $37^{\circ} \mathrm{C}$, the medium was replaced with $150 \mu \mathrm{L}$ DMSO, and the cell viability was measured by reading the plates at $490 \mathrm{~nm}$ using Microplate Reader (Thermo Fisher Scientific).

\section{Cell viability assay and measurement of intracellular ROS levels with and without ROS inhibitor NAC}

NAC, a ROS inhibitor, was applied to probe whether ROS was involved in the drug release process. A549 cells in a 96-well plate were preincubated with $100 \mu \mathrm{L}$ FBS-free RPMI 1640 medium containing NAC ( $5 \mathrm{mM})$ for $3 \mathrm{~h}$ before replacement with same volume of medium containing various 
doses of Cur and PPHC with and without NAC. After $24 \mathrm{~h}$ incubation, medium was replaced with $100 \mu \mathrm{L}$ fresh FBSfree RPMI 1640 medium to avoid influence of NAC and then $20 \mu \mathrm{L}$ MTT reagent was added. After $4 \mathrm{~h}$ incubation, cells were processed as described earlier in cytotoxicity study.

Oxidative-sensitive fluorescent probe 2,7-dichlorodihydrofluoroscein diacetate (DCFH-DA) was applied to detect ROS production. ${ }^{28}$ DCFH-DA, a cell permeable dye, is first converted into the polar derivative DCFH by cellular esterases, and DCFH is then turned into a highly fluorescent compound after activated by generated ROS. In brief, A549 cells were seeded in a 24 -well plate with $1 \times 10^{5}$ per well. Twenty-four hours later, the cell were treated with Cur and PPHC $\left(\mathrm{C}_{\text {cur }}=20 \mu \mathrm{g} / \mathrm{mL}\right)$ in the absence and presence of NAC ( $5 \mathrm{mM})$. Cells untreated, processed with $0.5 \%$ DMSO, and incubated with $5 \mathrm{mM} \mathrm{NAC}$ and PPH were used as negative controls. The group treated with diluted Rosup (50 mg/mL, supplied in the ROS assay kit; Beyotime Institute of Biotechnology, Nanjing, China) were applied as positive control following the manufacturers' protocols. ${ }^{29}$ After $24 \mathrm{~h}$ treatment, the cells were washed with PBS for two times and further incubated with DCFH-DA in the dark for $20 \mathrm{~min}$. Then the cells were washed with FBS-free RPMI 1640 medium for three times to remove excess DCFH-DA and collected after trypsinization. Cells treated with the same formulation without subsequent DCFH-DA incubation were also collected for basal fluorescence measurement. All samples were then analyzed by flow cytometry, and the percentage of positive cell generating ROS was expressed as percentage of population of positive control. Each experiment was performed in triplicate.

\section{In vitro cellular uptake of PPHC nanoparticles and cell imaging}

A549 cells were seeded in a 24 -well plate with $1 \times 10^{5}$ per well and cultivated in $1 \mathrm{~mL}$ RPMI 1640 medium containing 10\% FBS for $24 \mathrm{~h}$ at $37^{\circ} \mathrm{C}$ in a humidified atmosphere of $5 \% \mathrm{CO}_{2}$. Then the medium was replaced with $1 \mathrm{~mL}$ fresh FBS-free RPMI 1640 medium containing a desired amount of PPHC. The group untreated or incubated with PPH only was used as negative controls. Four hours later, cells were washed with PBS for three times and replaced with fresh FBS-free RPMI 1640 medium. The fluorescence was observed and imaged by fluorescent inverted microscope (TI-S; Nikon, Tokyo, Japan). Then, cells were trypsinized and resuspended in $500 \mu \mathrm{L}$ FBS-free RPMI 1640 medium for flow cytometry analysis (BD Accuri C6, BD, Franklin Lake, NJ, USA). Each experiment was performed in triplicate.
Confocal laser scanning microscopy (CLSM) study was also utilized for intracellular tracking of the nanoparticle. In brief, A549 cells were seeded on glass bottom Petri dishes and cultivated in $1 \mathrm{~mL}$ RPMI 1640 medium overnight. Then the medium was replaced with FBS-free RPMI 1640 medium containing PPHC nanoparticle $\left(\mathrm{C}_{\text {cur }}=20 \mu \mathrm{g} / \mathrm{mL}\right)$. At predetermined time intervals, cells were washed twice with PBS and incubated with Lysotracker red at $37^{\circ} \mathrm{C}$ for $1 \mathrm{~h}$. After removing the medium and being washed with $\mathrm{PBS}$, cells were stained with Hoechst 33442 for $10 \mathrm{~min}$ and then fixed with $4 \%$ paraformaldehyde. Fluorescence images of cells were taken by CLSM (FluoView ${ }^{\mathrm{TM}}$ FV1000 fluorescence microscope, Olympus Corp., Tokyo, Japan).

\section{Analysis of cell apoptosis by Annexin V- fluorescein isothiocyanate (FITC)/ propidium iodide $(\mathrm{PI})$ staining}

A549 cells were cultivated in a six-well plate with $2 \times 10^{5}$ each well for $24 \mathrm{~h}$. One milliliter of FBS-free RPMI 1640 medium containing Cur and PPHC $\left(\mathrm{C}_{\mathrm{Cur}}=20 \mu \mathrm{g} / \mathrm{mL}\right)$ were added into each well and incubated for $24 \mathrm{~h}$. The untreated cell was used as a negative control. Then the medium was removed, and the cells were washed with PBS for two times. After trypsinization, the cells were stained with the Annexin V-FITC Apoptosis Detection Kit (KeyGEN BioTECH, Nanjing, China) as the manufacturer recommended. The fluorescence of sample was then determined by flow cytometry.

For reconfirmation of enhanced stability of Cur in PPHC nanoparticles and its important effect on Cur-induced cell apoptosis, same operation was adopted except that Cur and PPHC nanoparticles were first pretreated with equal volume of PBS and incubated in the dark for $8 \mathrm{~h}$ before loaded into six-well plate.

\section{Statistic analysis}

All the experimental data were presented as mean values \pm standard error of mean. The unpaired $t$-test was utilized to determine the statistical significance of differences among groups. $P<0.05$ was considered as significant.

\section{Results and discussion Preparation of PPHC nanoparticles}

The mPEG-decorated PAA was synthesized with the same method reported before. ${ }^{22} \mathrm{mPEG}-\mathrm{NH}_{2}$ was incorporated into PAA via an amidation reaction, and ${ }^{1} \mathrm{H}$ NMR was applied for compositional confirmation. As shown in Figure 2, 3.63 and $3.38 \mathrm{ppm}$ resonance peaks were assigned to the protons of $\mathrm{CH}_{2}-\mathrm{CH}_{2}-\mathrm{O}$ - and $\mathrm{CH}_{3}-\mathrm{O}-$ of PEG, respectively, while 2.37 and $1.6-1.9 \mathrm{ppm}$ were ascribed to the protons of 


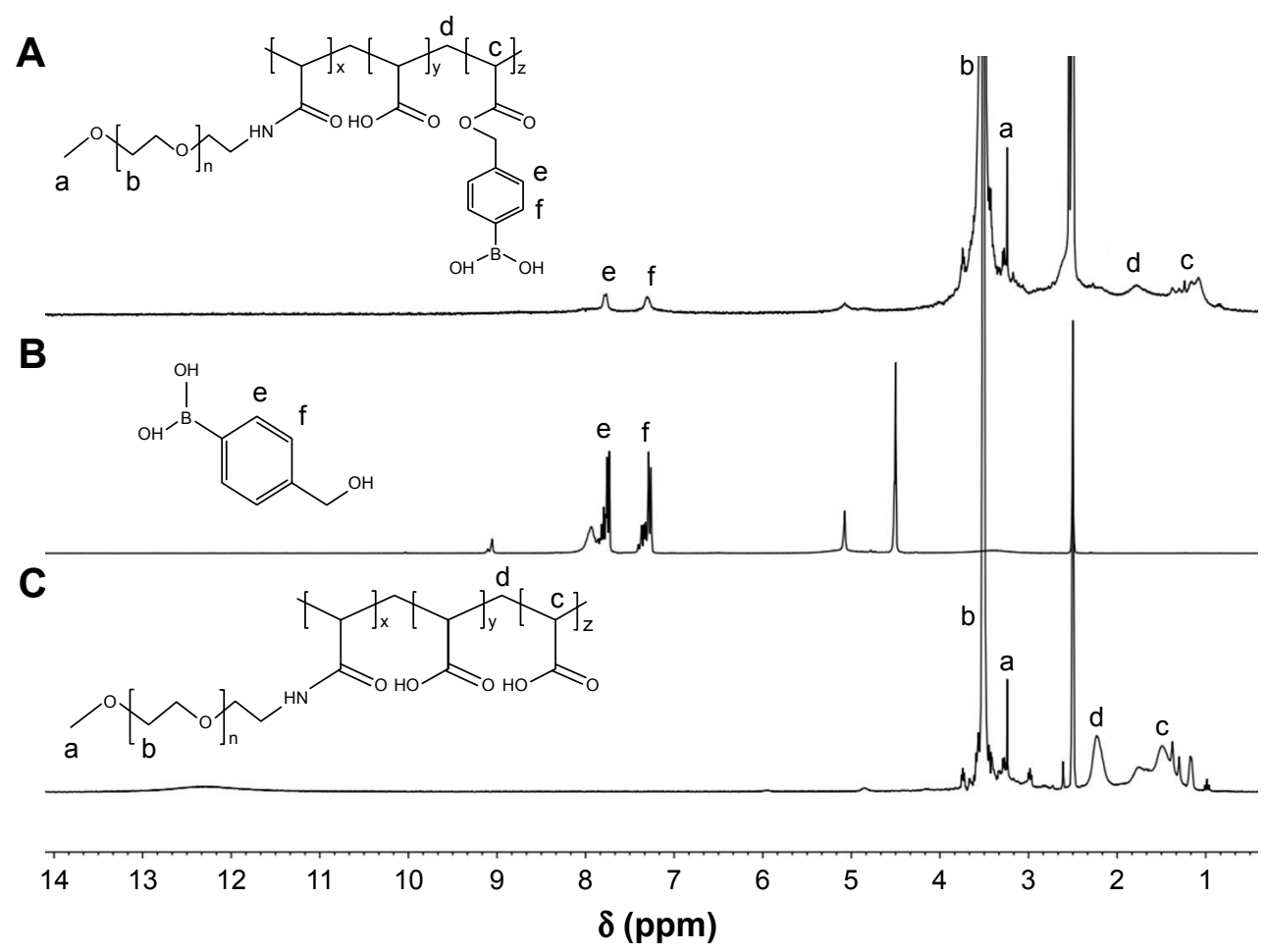

Figure 2 'H NMR spectra of (A) PPH, (B) HPBA, and (C) PP in DMSO-d.

Abbreviations: 'H NMR, 'H nuclear magnetic resonance spectroscopy; PPH, 4-(hydroxymethyl) phenylboronic acid-modified PEG-grafted poly(acrylic acid) polymer; HPBA,

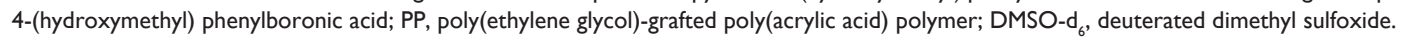

$-\mathrm{CH}_{2}-\mathrm{CH}-\mathrm{COO}-$ and $-\mathrm{CH}_{2}-\mathrm{CH}-\mathrm{COO}-$ of PAA, respectively. The calculated molar conjugation ratio between PAA and PEG was 1:1.3. HPBA was linked to mPEG-PAA through an ester bond, and the ${ }^{1} \mathrm{H}$ NMR spectra was represented in Figures $2 \mathrm{~A}$ and $\mathrm{B}$. The intense resonance peaks appearing at 7.34 and $7.78 \mathrm{ppm}$ were assigned to the aromatic protons of HPBA, which suggested that HPBA was successfully modified to mPEG-PAA. The HPBA-grafting degree of PPH calculated according to the calibration curve in DMSO was $38 \%$.

As Cur could coordinate with boronic acid in methanol, we first mixed Cur (dissolved in methanol) with PPH (in DMSO) and stirred for $4 \mathrm{~h}$. Then the PPHC nanoparticles were obtained by distributing the mixture into deionized water and dialyzed against water.

DL \% in the nanoparticles monitored per calibration curve of Cur in ethanol was $9.9 \%$ and EE\% was $65 \%$. This suggests that the specific interaction between boronic acid and Cur could prompt the encapsulation of Cur into nanoparticles. At the same time, nanoparticle formed by mixing Cur with PPH showed a deep red color, which was different from the orange color of Cur aqueous solution and mixture of Cur and PP (Figure 3A), and is in conformity with the result reported by Wimmer and Goldbach. ${ }^{30}$ All of these results indicated that Cur successfully coordinated with boronic acid-containing polymer PPH.
For further confirmation of the specific interaction between boronic acid and Cur, ${ }^{1} \mathrm{H}$ NMR was also applied. As shown in Figure $3 \mathrm{~B}$, an upfield shift to $6.3 \mathrm{ppm}$ ascribed to the $\gamma$-proton of the di-ketone in Cur was observed compared to that in Cur monomer, and shift in same field was reported by Mitra et al. ${ }^{31}$ This validated the coordination effect between Cur and boronic acid. Besides, as revealed in Figure 3C, Cur complexed in the nanoparticle PPHC exhibited a maximum absorption intensity at $460 \mathrm{~nm}$, while Cur aqueous solution displayed an intense optical absorption at $420 \mathrm{~nm} .{ }^{32}$ This red shift in the absorption peaks further verified the influence of boronic acid on Cur. Meanwhile, the fluorescence spectra in Figure 3D suggested that complexation with boronic acid-containing polymer quenched the fluorescence of free Cur as reported in platinum (II)-Cur ${ }^{31}$ and copper (II)-Cur ${ }^{33}$ complexes and indicated that coordination with the di-ketone part of Cur might lead to its weaken optical feature or quenched effects.

\section{Physicochemical properties of the PPHC nanoparticle}

According to the results in Figure 4A, the size of the wellformed nanoparticle was $\sim 163.8 \mathrm{~nm}$, and the corresponding polydispersity index was 0.315 . Morphology in Figure 4B visualized by TEM revealed uniform spherical particles. This makes it possible to take advantage of EPR effect ${ }^{34}$ to 
A
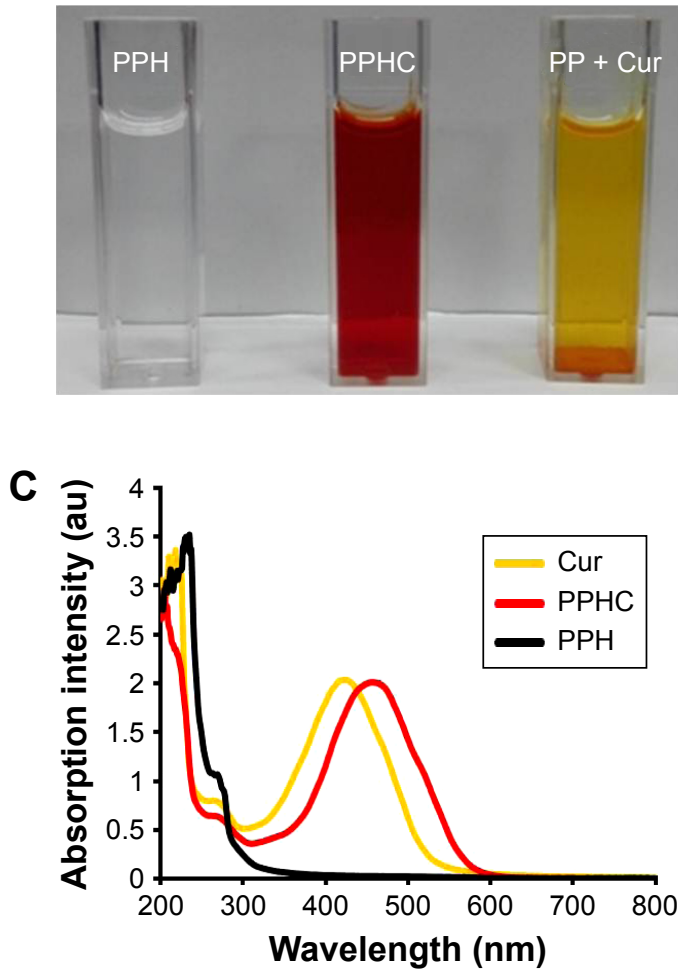

B

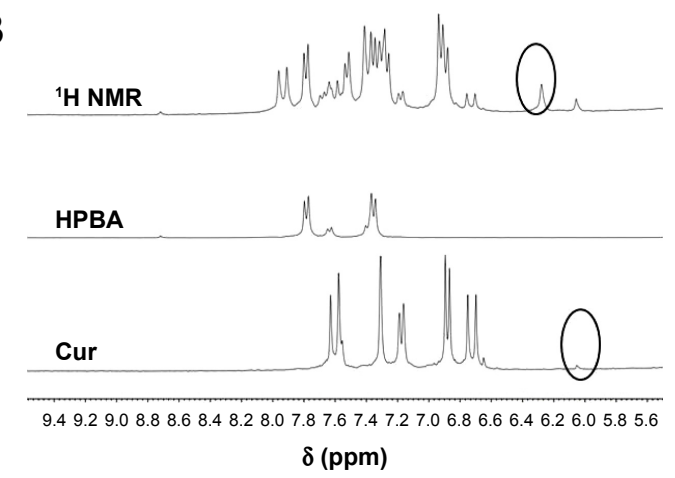

D

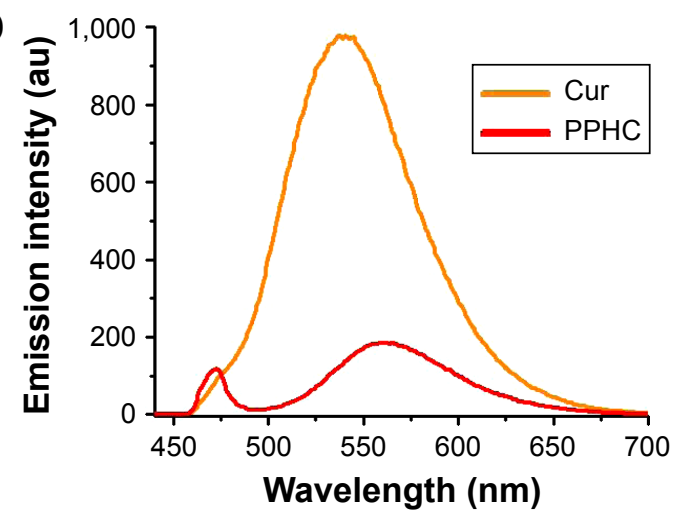

Figure 3 Analysis of the interaction between the Cur and HPBA.

Notes: (A) Color difference of the PPH solution, the PPHC nanoparticle, and the mixture of Cur and PP. (B) 'H NMR spectra of the mixture of HPBA and Cur, HPBA and Cur in $\mathrm{CD}_{3} \mathrm{OD} / \mathrm{DMSO}-\mathrm{d}_{6}(\mathrm{I}: \mathrm{I})$ solvent. (C) UV-Vis spectra of Cur, PPHC, and PPH in water $\left(\mathrm{C}_{\text {cur }}=20 \mu \mathrm{g} / \mathrm{mL}\right.$, Cur was solubilized with $5 \%$ DMSO). (D) Fluorescence spectra of PPHC and free Cur in 50\% DMSO aqueous solution $\left(C_{\text {cur }}=20 \mu \mathrm{g} / \mathrm{mL}\right)$. The excitation wavelength is $474 \mathrm{~nm}$.

Abbreviations: Cur, curcumin; HPBA, 4-(hydroxymethyl) phenylboronic acid; PPH, 4-(hydroxymethyl) phenylboronic acid-modified PEG-grafted poly(acrylic acid) polymer; PPHC, curcumin-coordinated reactive oxygen species-responsive nanoparticle; PP, poly(ethylene glycol)-grafted poly(acrylic acid) polymer; 'H NMR, 'H nuclear magnetic resonance spectroscopy; $\mathrm{CD}_{3} \mathrm{OD}$, tetradeuteromethanol; DMSO, dimethyl sulfoxide; DMSO- $\mathrm{d}_{6}$, deuterated dimethyl sulfoxide.

target the tumor site and exert its therapeutic efforts. Besides, the zeta potential was $-0.31 \mathrm{mV}$, a nearly neutral-charged surface, together with the shielding effect of mPEG segment could impart the PPHC nanoformulation with prolonged circulation time. ${ }^{35,36}$

The physicochemical characteristic of nanoparticles such as particle size directly influences the cellular uptake and distribution, as well as therapeutic efficiency. ${ }^{37}$ Particle sizes in different medium at different time intervals were also measured. No significant size fluctuations in Figures 4C-E were observed, indicating that the nanoparticles were stable at $4^{\circ} \mathrm{C}$ and in the presence of PBS or in RPMI 1640 medium containing $10 \%$ FBS. However, the particle size tended to increase after the addition of $\mathrm{H}_{2} \mathrm{O}_{2}(2 \mathrm{mM})$ (Figure $4 \mathrm{~F}$ ), which illustrated that $\mathrm{H}_{2} \mathrm{O}_{2}$ triggered the degradation of boronic acid to destruct the structure of the nanoparticle and consequently accelerated drug release. ${ }^{38}$

Furthermore, it is reasoned that the absorbance intensity of Cur would decrease with the degradation of Cur in PBS, so the absorption spectra of the nanoparticle in PBS was monitored at predetermined time intervals. ${ }^{31}$ As revealed in Figure 5A-C, in comparison with pure Cur aqueous solution, which is known to degrade $60 \%$ within $25 \mathrm{~min},{ }^{24,39}$ more than half of Cur in PPHC group were protected even after $11 \mathrm{~h}$ incubation with $\mathrm{PBS}$ at $37^{\circ} \mathrm{C}$. The enhanced stability of Cur in PPHC could be contributed by the formation of self-assembly, which protected it from deprotonation and fragmentation in physiological conditions.

\section{In vitro Cur release of PPHC nanoparticles}

As the color change was utilized as an analytic method for boron detection, ${ }^{23}$ here, the corresponding color change of PPHC after incubation with $2 \mathrm{mM} \mathrm{H}_{2} \mathrm{O}_{2}$ for various time intervals was photographed to show the drug release profile. As illustrated in Figure 6A, the color of PPHC nanoparticles gradually turned to bright orange, which was the same as pure Cur solution. Four hours later, Cur released from PPHC nanoparticles under $\mathrm{H}_{2} \mathrm{O}_{2}$ tended to aggregate as there were precipitates in the $\mathrm{H}_{2} \mathrm{O}_{2}$ group after centrifugation (Figure 6B). Moreover, the results presented in Figure $6 \mathrm{C}$ prove that the maximum absorption wavelength shift to $420 \mathrm{~nm}$, where the pure Cur exhibited maximal absorption intensity. All those results verified that $\mathrm{H}_{2} \mathrm{O}_{2}$ destroyed the interaction between 


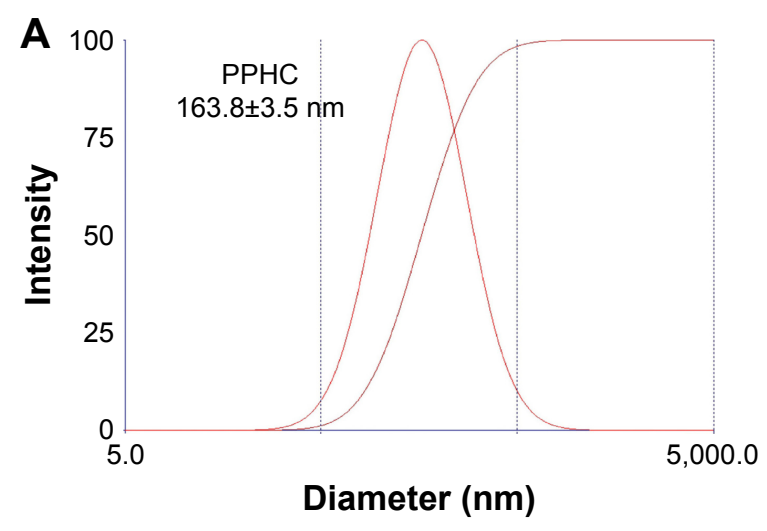

B
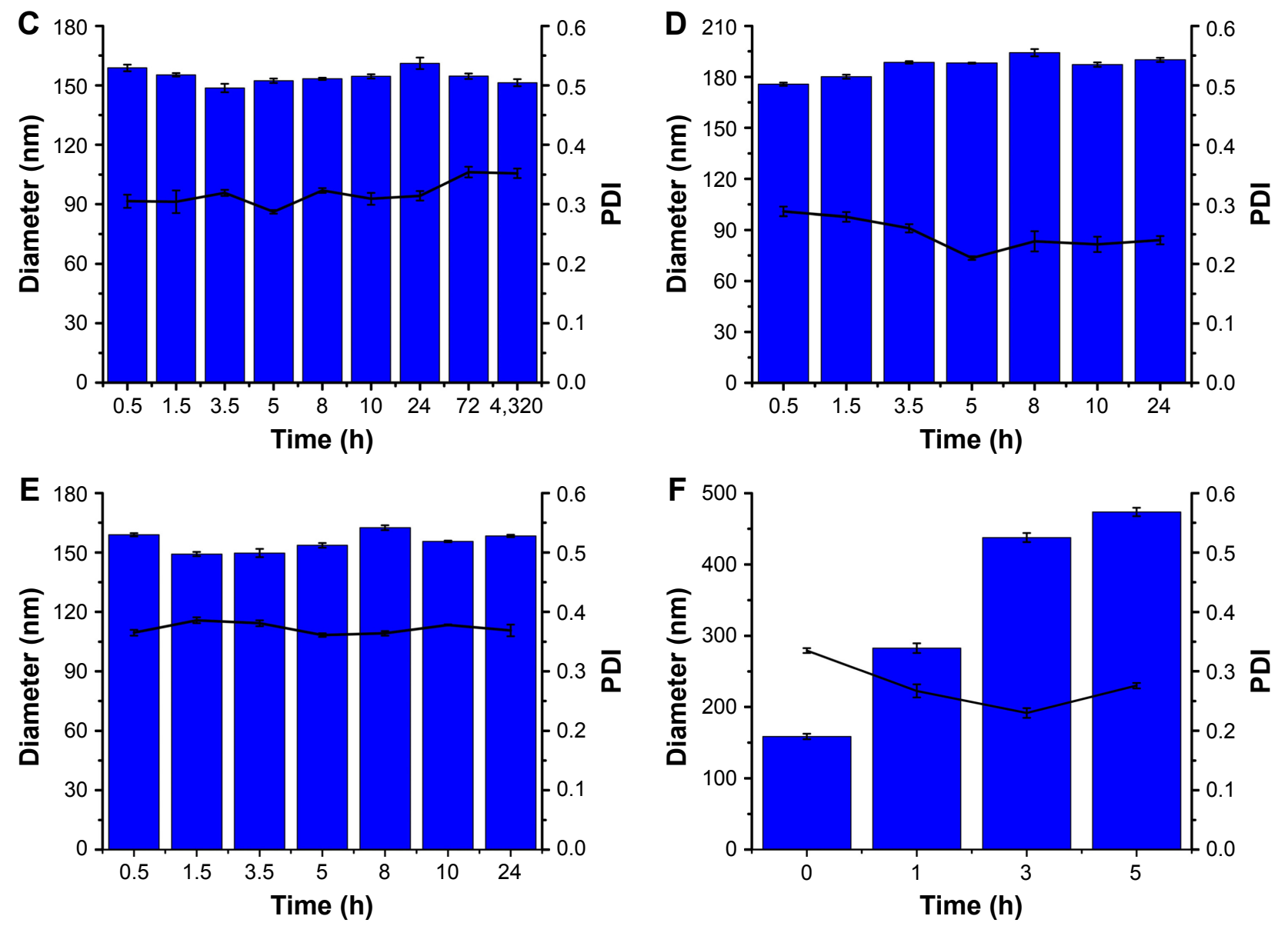

Figure 4 Characterization of the PPHC nanoparticle.

Notes: (A) Size measurement by DLS. (B) Morphology reflected by TEM. (C) Size stability of PPHC while stored at $4^{\circ} \mathrm{C}$, (D) in the presence of PBS, and (E) in the presence

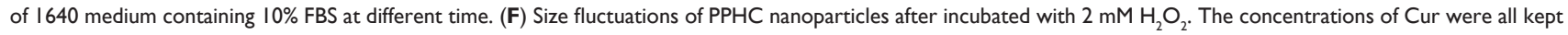
at $35 \mu \mathrm{g} / \mathrm{mL}$. The data are shown as mean \pm standard error of mean $(n=3)$.

Abbreviations: PPHC, curcumin-coordinated reactive oxygen species-responsive nanoparticle; DLS, dynamic light scattering; TEM, transmission electron microscopy; PBS, phosphate-buffered saline; FBS, fetal bovine serum; $\mathrm{H}_{2} \mathrm{O}_{2}$, hydrogen peroxide; Cur, curcumin; PDI, polydispersity index.

Cur and boronic acid and triggered the release of Cur from PPHC nanoparticles.

\section{In vitro cytotoxicity of PPHC nanoparticles}

For in vitro therapeutic efficiency evaluation, the cell viability of A549 cell was measured through MTT assay. A549 cells were treated with PPH, Cur, and PPHC, while the group with nontreatment and processed with $0.5 \%$ DMSO was considered as negative controls. As presented in Figure 7A and B, the group treated with PPH showed negligible cytotoxicity, which demonstrated that PPH was highly biocompatible and safe. However, the group treated with PPHC showed both doseand time-dependent cytotoxicity like the Cur-treated group. 
A

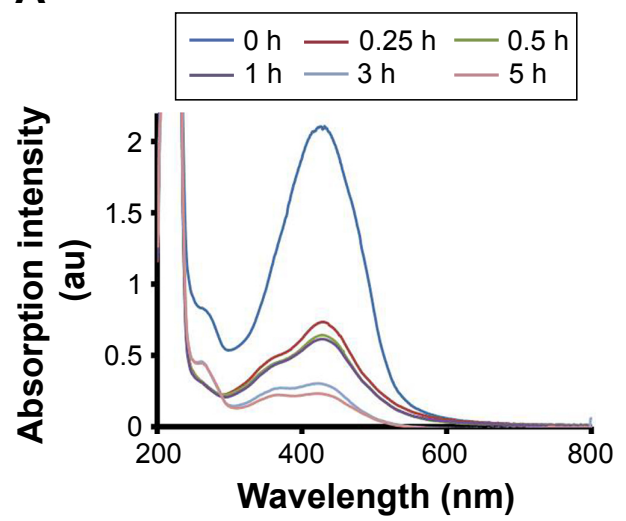

B
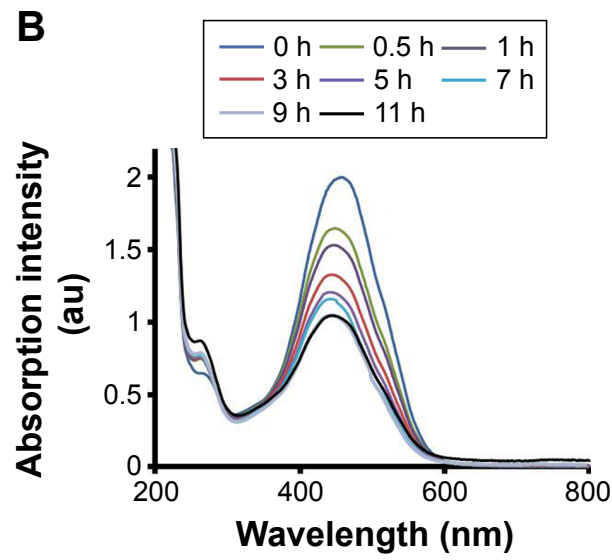

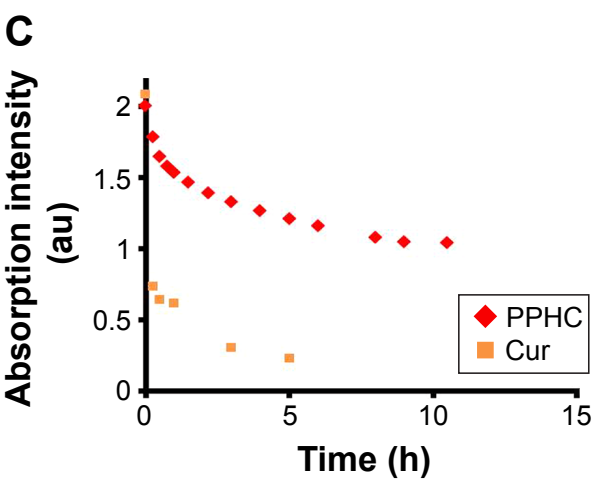

Figure $\mathbf{5}$ Stability of Cur and PPHC in PBS.

Notes: Full wavelength scanning of (A) Cur and (B) PPHC in PBS in the dark. (C) Time-dependent absorption intensity change at maximal absorption wavelength of Cur and PPHC in PBS ( $C_{\text {cur }}=20 \mu \mathrm{g} / \mathrm{mL}$, Cur was solubilized with $5 \%$ DMSO in Cur group).

Abbreviations: Cur, curcumin; PPHC, curcumin-coordinated reactive oxygen species-responsive nanoparticle; PBS, phosphate-buffered saline; DMSO, dimethyl sulfoxide.

\section{A}

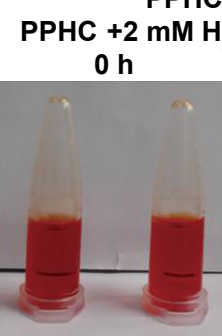

$1 \mathrm{~h}$

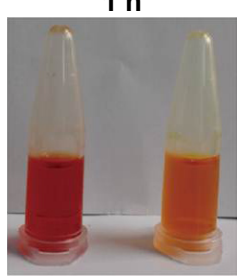

$3 \mathbf{h}$

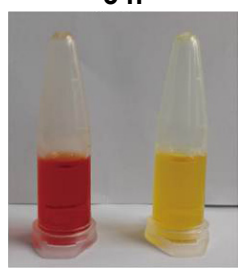

PPHC $\mathrm{H}_{2} \mathrm{O}_{2} \mathrm{PPHC}+2 \mathrm{mM} \mathrm{H}_{2} \mathrm{O}_{2}$ $0.5 \mathrm{~h}$

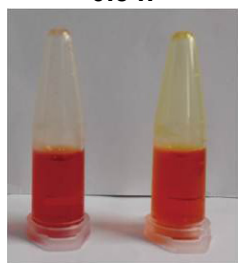

$2 \mathrm{~h}$

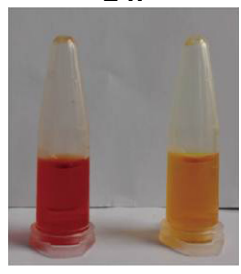

$4 \mathrm{~h}$

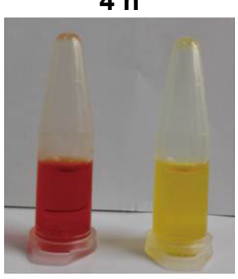

B

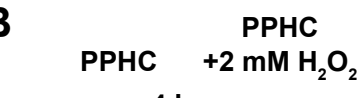

$4 \mathrm{~h}$
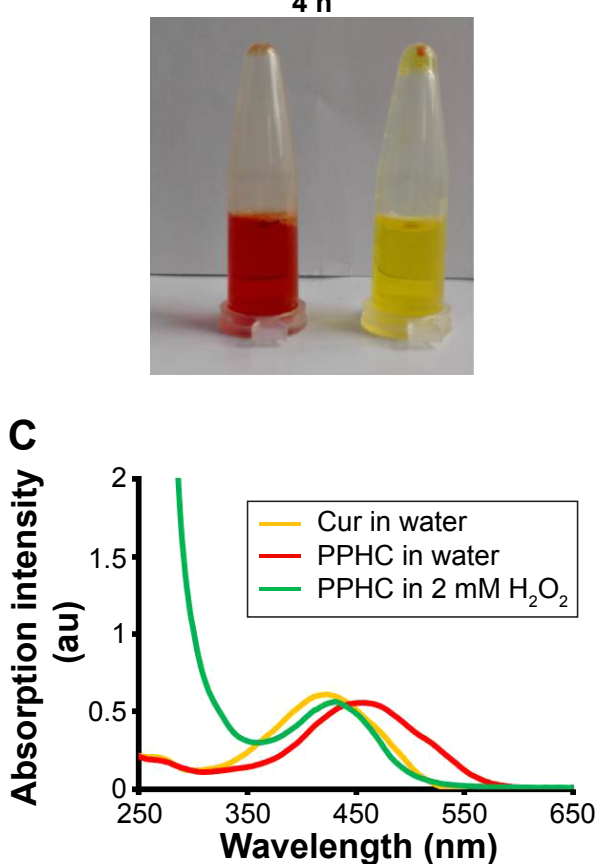

Figure 6 In vitro $\mathrm{H}_{2} \mathrm{O}_{2}$-stimulated drug release assay.

Notes: (A) Time-dependent color change of PPHC nanoparticles while incubated with $2 \mathrm{mM} \mathrm{H}_{2} \mathrm{O}_{2}$. (B) Photographs of PPHC nanoparticles centrifuged at 3,000 rpm for 3 min after incubation with $2 \mathrm{mM} \mathrm{H}_{2} \mathrm{O}_{2}$ for $4 \mathrm{~h}$. (C) Recovered maximal absorption wavelength of Cur in PPHC nanoparticle after incubated with 2 mM $\mathrm{H}_{2} \mathrm{O}_{2}$ for $4 \mathrm{~h}$. Abbreviations: $\mathrm{H}_{2} \mathrm{O}_{2}$, hydrogen peroxide; PPHC, curcumin-coordinated reactive oxygen species-responsive nanoparticle; Cur, curcumin. 

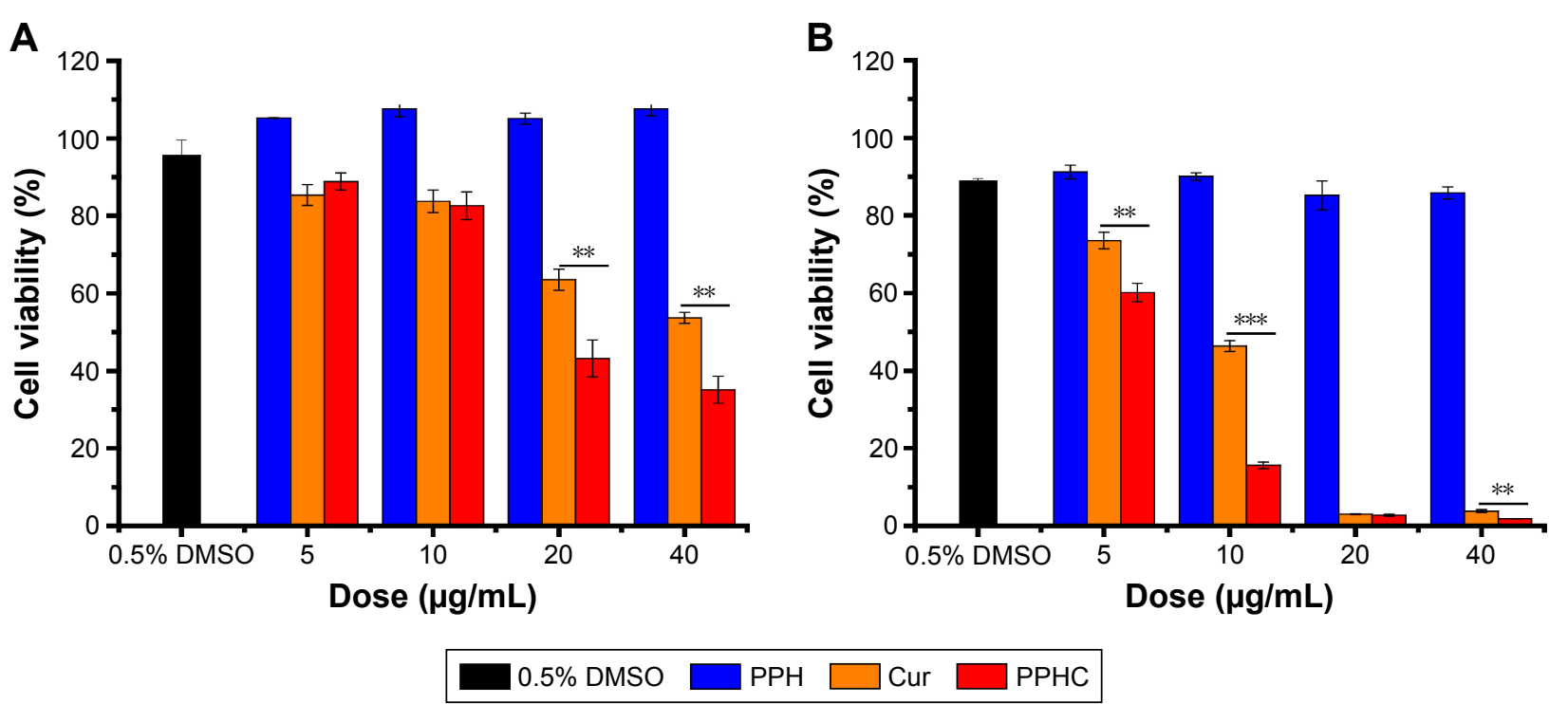

Figure 7 In vitro cell viability of A549 cells treated with Cur, PPH, and PPHC nanoparticles at various concentrations for (A) $24 \mathrm{~h}$ and (B) 72 h. Notes: The data are shown as mean \pm standard error of mean $(n=3)$. $* * P<0.01$, $* * * P<0.001$ for significance difference.

Abbreviations: Cur, curcumin; PPH, 4-(hydroxymethyl) phenylboronic acid-modified PEG-grafted poly(acrylic acid) polymer; PPHC, curcumin-coordinated reactive oxygen species-responsive nanoparticle; DMSO, dimethyl sulfoxide.

Moreover, compared to Cur group, the cell viability decreased more sharply as the concentration of Cur increased in PPHC group. For example, after $24 \mathrm{~h}$ treatment, the cell viability was $43 \%$ in PPHC-treated group $\left(\mathrm{C}_{\text {cur }}=20 \mu \mathrm{g} / \mathrm{mL}\right)$, while it was $63 \%$ for Cur group. This indicated that PPHC nanoparticles had enhanced therapeutic efforts, which could partly be ascribed to the increased cellular uptake contributed by using nanovehicles as delivery systems.

\section{Cell viability and DCFH-DA assay with and without ROS inhibitor NAC}

NAC, an antioxidant reported to strongly decrease the cellular level of $\mathrm{H}_{2} \mathrm{O}_{2},{ }^{17}$ was applied to probe the effect of ROS on PPHC nanoparticles. As shown in Figure 8A, cell viability was significantly increased in the presence of NAC in PPHC treatment group, even in a highly concentration of $20 \mu \mathrm{g} / \mathrm{mL}$. This verified that decreased ROS content impeded the release of Cur and prevented it from exerting its antitumor effect. At the same time, cell viability in Cur group also increased in the presence of $5 \mathrm{mM}$ NAC, which implied that free Cur might partly exhibit its cytotoxic effect in A549 through ROS signaling pathway as Yang et $\mathrm{al}^{7}$ reported, and ROS suppression by NAC protected cells from damage by Cur. However, the suppressive effect of NAC in Cur group disappeared as the concentration of Cur increased to $20 \mu \mathrm{g} / \mathrm{mL}$, while the presence of NAC effectively protected cells from the PPHC treatment at the same concentration. These results further validated that the ROS inhibition by NAC could hamper the tumor-suppressing behavior of PPHC nanoparticles by significantly hindering the release of Cur from the PPHC nanoparticles, which further guaranteed its targeting ability for ROS-elevated cancer cells.

To reconfirm that ROS was involved in cell apoptotic process induced by PPHC nanoparticles, ROS levels in A549 cells treated with Cur and PPHC without and in the presence of $5 \mathrm{mMNAC}$ were measured by DCFH-DA assay. As shown in Figure 8B, the fluorescence intensity was relatively low in cells treated with $5 \mathrm{mM}$ NAC in comparison to cells treated with DCFH-DA only indicating that NAC addition successfully decreased the ROS in A549 cell, which demonstrated its potential to act as ROS inhibitor. ROS levels in cells treated with PPH have no significant difference to the cells with DCFH-DA treatment and confirmed that the highly compatible PPH had no influence on intracellular ROS levels. Nevertheless, ROS level was upregulated in Cur group without NAC, and NAC addition inhibited ROS production by Cur. These findings validated that Cur induced A549 cell apoptosis via ROS signaling pathway as aforementioned in Figure 8A. Nevertheless, much more decrease of ROS was observed in the PPHC group with NAC. This suggested that NAC, though might suppress Cur-stimulated ROS generation, prominently impeded Cur release that further prevent Cur from exerting its therapeutic effect through ROS signaling pathway. These were in line with the phenomenon observed in cell viability assay and verified that ROS was important for therapeutic use of PPHC nanoparticles. 

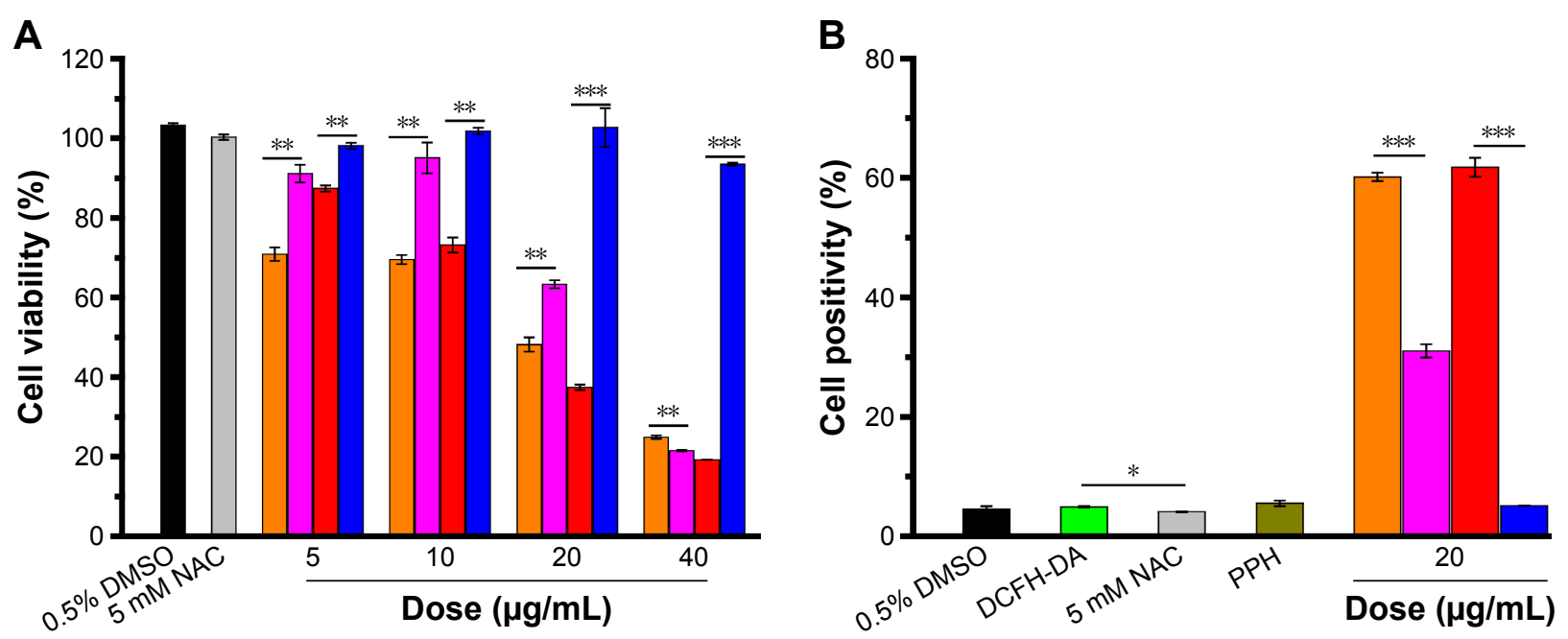

$\square$ Cur $\square$ Cur +5 mM NAC

PPHC

PPHC +5 mM NAC

Figure 8 Cell viability and ROS levels in A549 cells treated with various doses of Cur and PPHC without and in the presence of ROS inhibitor NAC (5 mM). Notes: (A) Cell viability of A549 cells treated with various doses of Cur and PPHC without and with NAC for 24 h. (B) The percentage of cell positivity from a DCFH-DA assay for A549 cells after $24 \mathrm{~h}$ treatment with Cur and PPHC ( $\left.\mathrm{C}_{\text {cur }}=20 \mu \mathrm{g} / \mathrm{mL}\right)$ in the absence of and presence of NAC (5 mM). The data are shown as mean \pm standard error of mean $(\mathrm{n}=3)$. $* \mathrm{P}<0.05, * * \mathrm{P}<0.0 \mathrm{I}$, and $* * * P<0.00 \mathrm{I}$ for significance difference.

Abbreviations: ROS, reactive oxygen species; Cur, curcumin; PPH, 4-(hydroxymethyl) phenylboronic acid-modified PEG-grafted poly (acrylic acid) polymer; PPHC, curcumin-coordinated reactive oxygen species-responsive nanoparticle; NAC, N-acetyl-cysteine; DCFH-DA, 2,7-dichlorodihydrofluoroscein diacetate; DMSO, dimethyl sulfoxide.

\section{In vitro cellular uptake of PPHC nanoparticle}

Taking advantage of the inherent green fluorescence of Cur, ${ }^{13,40}$ the cellular uptake of Cur mediated by PPHC nanoparticle was detected with fluorescence microscope and quantified by flow cytometry. A549 cells were incubated with medium containing PPH and PPHC. As shown in Figure 9A, $4 \mathrm{~h}$ later, the PPHC group at various concentrations presented increased fluorescence, while the PPH group with same polymer dose demonstrated no fluorescence signal under fluorescence microscope. These results indicated that Cur was successfully delivered into cancer cells by PPHC nanoparticle. Besides, quantitative analysis obtained via flow cytometry as expressed in Figure 9B reconfirmed a concentration-dependent cellular uptake trend of Cur through PPHC nanoparticles.

To further visualize the cell internalization of PPHC nanoparticles, CLSM study was performed. A549 cells were processed as aforementioned, and the images in Figure 10 demonstrated that the nanoparticles were endocytosed into the cells as more green spot appeared in cells $4 \mathrm{~h}$ later. Yellow spots in Figures 10C and D suggested that the PPHC nanoparticle mainly localized in lysosomes after $4 \mathrm{~h}$ incubation. ${ }^{13}$ After the next 8-h incubation, the PPHC nanoparticle were still in lysosome (Figures 10C and D). This indicated that the PPHC nanoparticle altered the distribution of Cur as Cur alone mainly localized on the cell membrane and nucleus. ${ }^{41}$

\section{Enhanced apoptosis induced by PPHC}

To examine whether Cur in PPHC nanoparticles has proapoptotic activity, Annexin V-FITC/PI staining was conducted. The percentage of double-positive cells for Annexin VFITC/PI staining was measured by flow cytometry, and the results were presented in Figure 11A. The total proportion of apoptotic cells was a little higher for PPHC group (84.2\% in PPHC vs $77.8 \%$ in Cur), and much more late apoptosis was induced by PPHC compared to Cur alone ( $73.3 \%$ vs $19.6 \%)$.

To verify that enhanced Cur stability in PPHC was important for causing cell apoptosis, Cur and PPHC were preprocessed with PBS in the dark for $8 \mathrm{~h}$ before added to treat cells. The results in Figure 11B demonstrated that the therapeutic efficiency of Cur group was obviously attenuated due to its highly degradation rate in PBS as described in stability assay (23.0\% with PBS vs $77.8 \%$ without PBS). In contrast, the proportion of apoptotic cells in the PPHC group was less affected by PBS pretreatment (47.6\% with PBS vs $84.2 \%$ without PBS). These results validated that PPHC nanoparticle improved the stability of Cur as observed in the stability assay in the "Physicochemical properties of the PPHC nanoparticle" section, and this was significant for the nanoformulation to exert antitumor efficiency. From all these results, the protective effect of Cur provided by PPHC nanoparticles was relatively weak, and very significant superiority was not observed. Nonetheless, it was understandable 

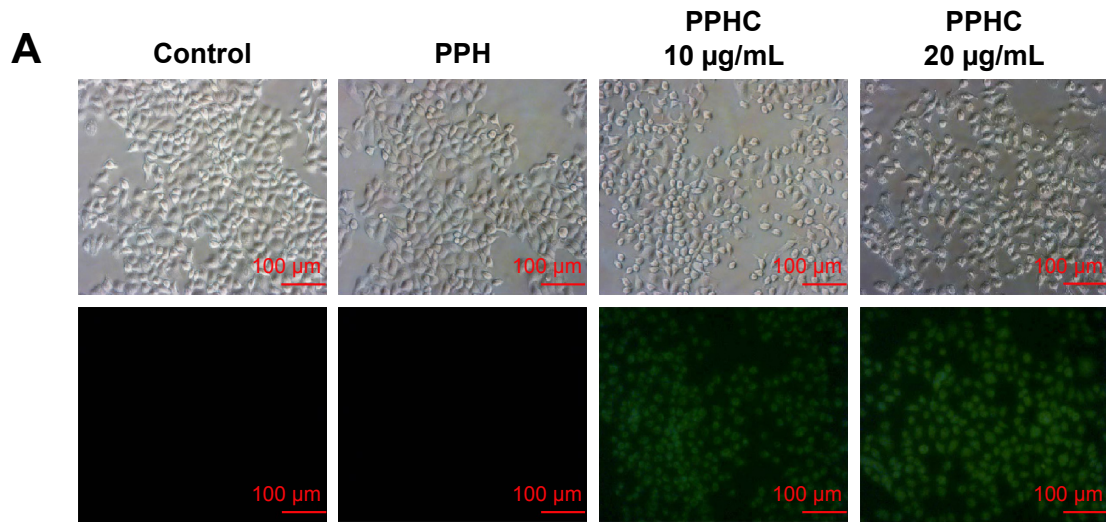

PPHC
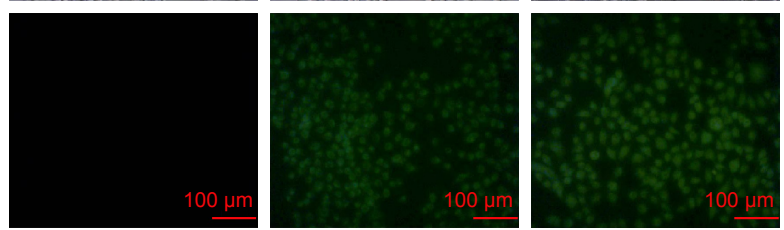

$30 \mu \mathrm{g} / \mathrm{mL}$

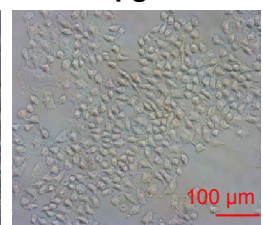

B

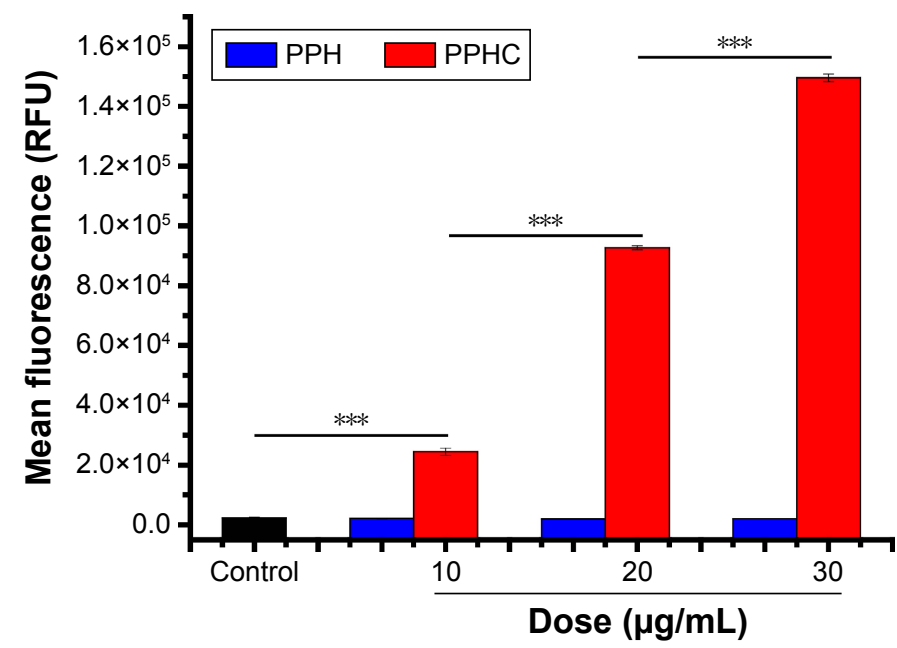

Figure 9 Cellular uptake of PPH and PPHC with different Cur concentrations in A549 cells.

Notes: (A) Fluorescence images of A549 cancer cells after treatment with PPH and PPHC for 4 h. Original magnification: 20x. Scale bar $=100 \mu m$. (B) Mean fluorescence intensity in FL2 of A549 cells treated with PPH and PPHC in different concentrations for $4 \mathrm{~h}$. The data are shown as mean \pm standard error of mean ( $=3$ ). $* * * P<0.00 \mathrm{I}$ for significance difference.

Abbreviations: PPH, 4-(hydroxymethyl) phenylboronic acid-modified PEG-grafted poly(acrylic acid) polymer; PPHC, curcumin-coordinated reactive oxygen speciesresponsive nanoparticle; Cur, curcumin; RFU, relative fluorescence units.

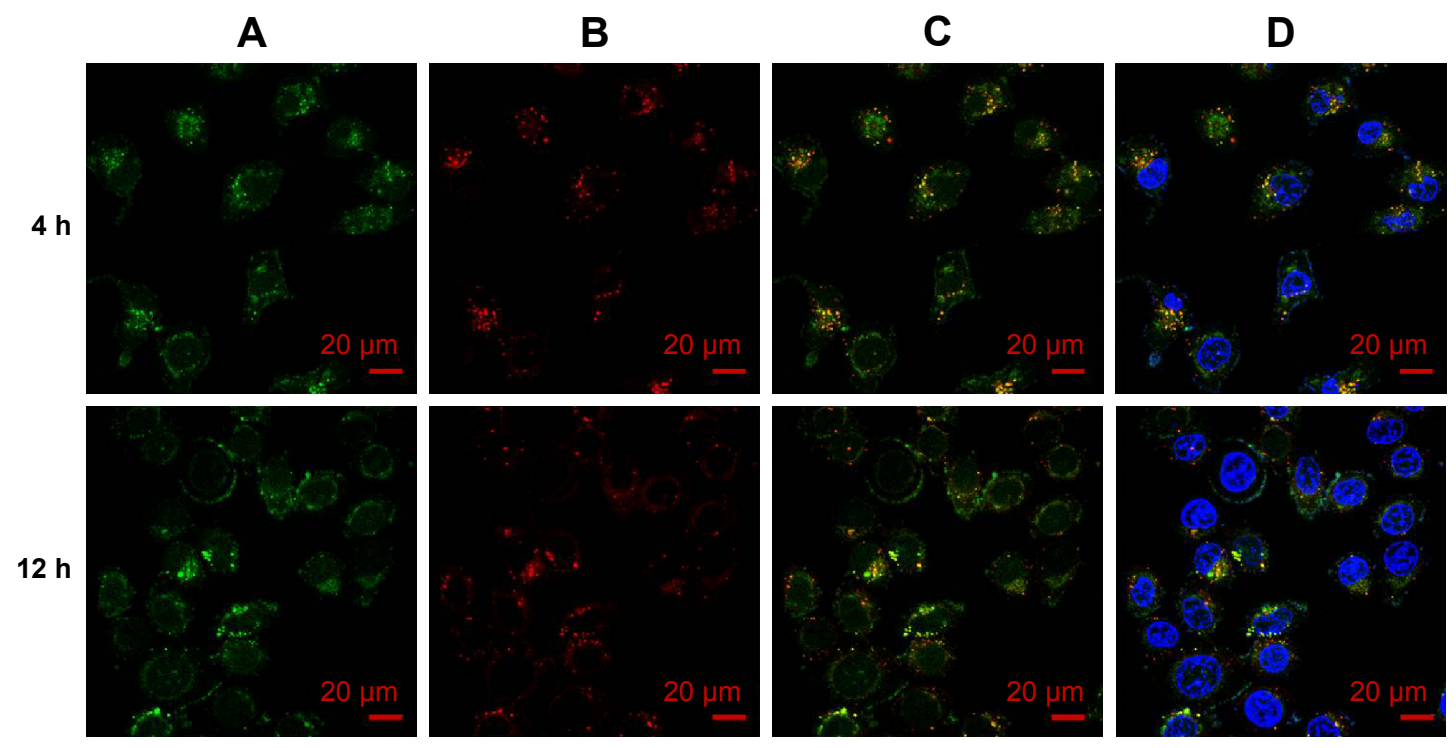

Figure 10 Intracellular localization of PPHC nanoparticles observed by confocal microscopy.

Notes: A549 cells were treated with PPHC $\left(C_{\text {Cur }}=10 \mu \mathrm{g} / \mathrm{mL}\right)$ for 4 and $12 \mathrm{~h}$. The images represents (A) PPHC channel, (B) lysotracker red channel, (C) overlap of (A) and (B), and (D) overlap of (C) and nuclear dye channel (blue), respectively.

Abbreviations: PPHC, curcumin-coordinated reactive oxygen species-responsive nanoparticle; Cur, curcumin. 
A

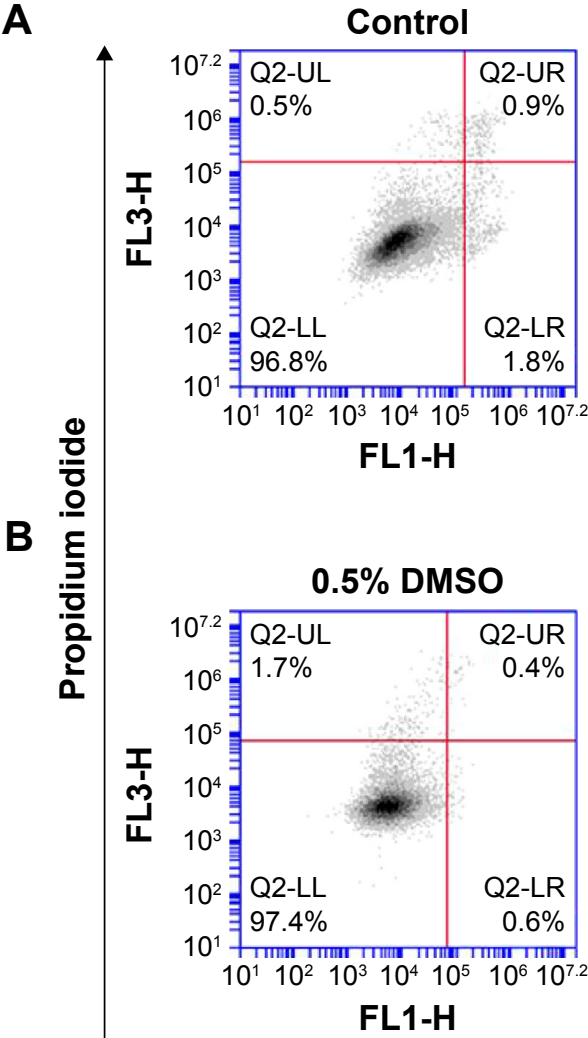

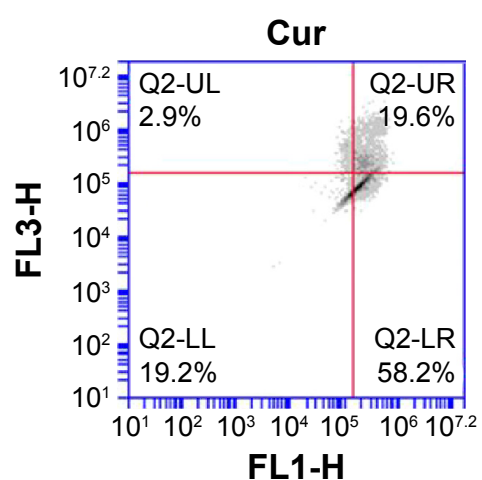
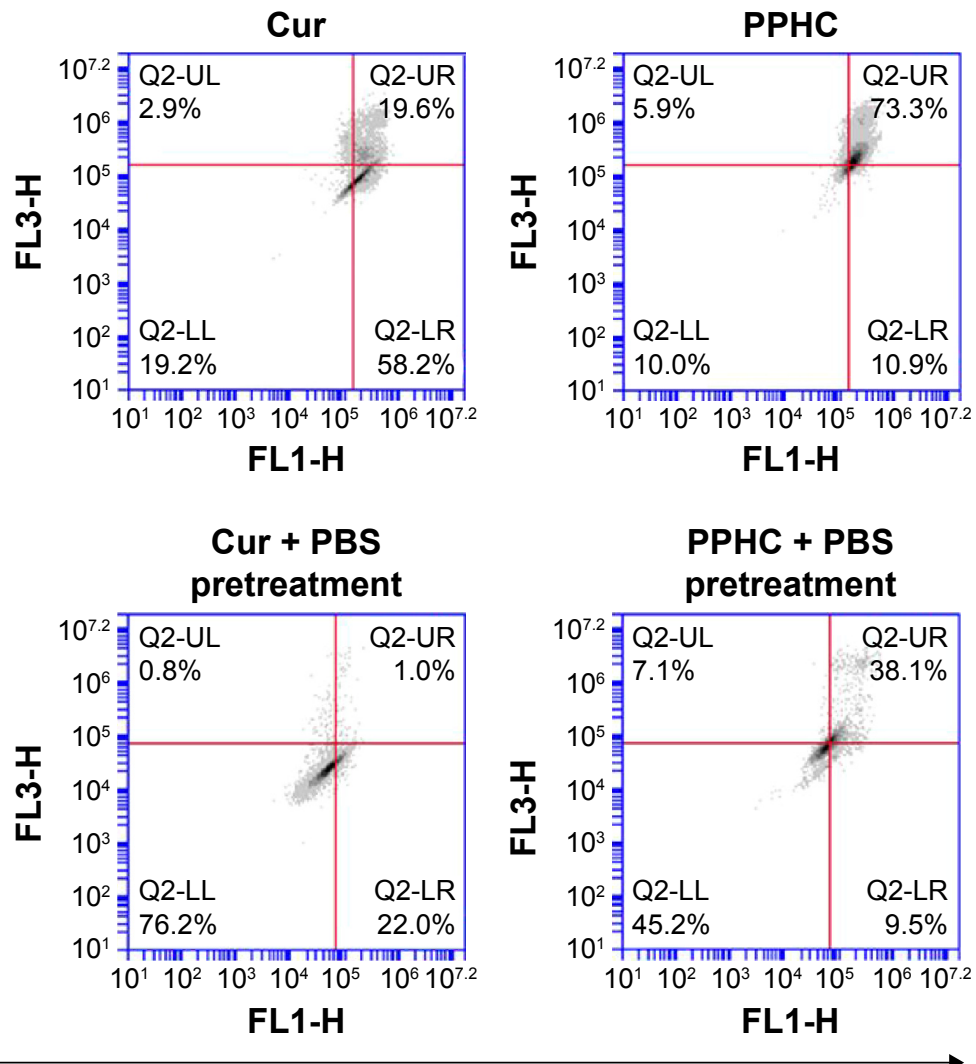

Annexin V-FITC

Figure I I Flow cytometry analysis of A549 cell apoptosis induced by Cur and PPHC (C Cur $\left._{2}=20 \mu \mathrm{g} / \mathrm{mL}\right)$ for $24 \mathrm{~h}$ using Annexin V-FITC/PI staining.

Notes: (A) Cur and PPHC were loaded directly without PBS incubation. (B) Cur and PPHC were loaded after incubation with PBS in the dark for $8 \mathrm{~h}$.

Abbreviations: Cur, curcumin; PPHC, curcumin-coordinated reactive oxygen species-responsive nanoparticle; FITC, fluorescein isothiocyanate; PI, propidium iodide; PBS, phosphate-buffered saline; DMSO, dimethyl sulfoxide.

considering that the coordination interaction between boronic acid was the dominant force in PPHC nanoparticles. As the coordination effect between Cur and boronic acid was only used for boron detection before, the development of PPHC nanoparticles shed light on fabrication of more stable stimuli-responsive nanoplatform based on the inherent properties of Cur.

\section{Conclusion}

Promoted by the coordination effect between boronic acid and Cur, a ROS-responsive polymeric nanoparticle was successfully fabricated for efficient Cur delivery into cancer cells. The well-dispersed spherical nanoparticles were capable to improve Cur stability at physiological environment and trigger the Cur release in response to $\mathrm{H}_{2} \mathrm{O}_{2}$. Moreover, ROS inhibition that obviously suppressed cytotoxic effect of the nanoparticles validated nanoparticles' targeting selectivity for high ROS cancer cells. Simultaneously, weak impact of PBS pretreatment on the PPHC group further proved that the enhanced Cur stability in the PPHC nanoparticle group was vital for exerting therapeutic efficiency. Overall, a ROS-responsive nanoparticle based on coordination interaction between boronic acid and Cur was prepared and can be a compelling approach to improve Cur stability. Besides, it also provided a new prospective for developing stable delivery carriers with on-demand release profiles of Cur under oxidative stress.

\section{Acknowledgments}

We thank the National Natural Science Foundation of China (grant nos 81573369, 21301191, 81570696, and 31270985), the Natural Science Foundation of Jiangsu Province (grant nos BK20130661 and BK20140659), and the Excellent Youth Foundation of Jiangsu Scientific Committee (BK20140029). This work was also supported by the Funds for the Priority Academic Program Development of Jiangsu Higher Education Institutions (PAPD), the National High Technology Research and Development Program 863 (grant nos 2012AA02A303 and 2015AA020314), the Fundamental Research Funds for the Central Universities (Z114037), and the Outstanding Youth Fund of Jiangsu Province of China (grant no BK20160031). 


\section{Disclosure}

The authors report no conflicts of interest in this work.

\section{References}

1. Gupta SC, Kismali G, Aggarwal BB. Curcumin, a component of turmeric: from farm to pharmacy. Biofactors. 2013;39(1):2-13.

2. Slavova-Kazakova AK, Angelova SE, Veprintsev TL, et al. Antioxidant potential of curcumin-related compounds studied by chemiluminescence kinetics, chain-breaking efficiencies, scavenging activity (ORAC) and DFT calculations. Beilstein J Org Chem. 2015;11:1398-1411.

3. Aggarwal BB, Kumar A, Bharti AC. Anticancer potential of curcumin: preclinical and clinical studies. Anticancer Res. 2003;23(1A): 363-398.

4. Kuttan R, Bhanumathy P, Nirmala K, George MC. Potential anticancer activity of turmeric (Curcuma longa). Cancer Lett. 1985;29(2): 197-202.

5. Shehzad A, Lee J, Lee YS. Curcumin in various cancers. Biofactors. 2013;39(1):56-68.

6. Reuter S, Eifes S, Dicato M, Aggarwal BB, Diederich M. Modulation of anti-apoptotic and survival pathways by curcumin as a strategy to induce apoptosis in cancer cells. Biochem Pharmacol. 2008;76(11): $1340-1351$

7. Yang CL, Ma YG, Xue YX, Liu YY, Xie H, Qiu GR. Curcumin induces small cell lung cancer NCI-H446 cell apoptosis via the reactive oxygen species-mediated mitochondrial pathway and not the cell death receptor pathway. DNA Cell Biol. 2012;31(2):139-150.

8. Anand P, Kunnumakkara AB, Newman RA, Aggarwal BB. Bioavailability of curcumin: problems and promises. Mol Pharm. 2007;4(6): 807-818.

9. Yallapu MM, Jaggi M, Chauhan SC. Curcumin nanoformulations: a future nanomedicine for cancer. Drug Discov Today. 2012;17(1-2):71-80.

10. Salem M, Rohani S, Gillies ER. Curcumin, a promising anti-cancer therapeutic: a review of its chemical properties, bioactivity and approaches to cancer cell delivery. RSC Adv. 2014;4(21):10815-10829.

11. Lee JJ, Lee SY, Park JH, Kim DD, Cho HJ. Cholesterol-modified poly (lactide-co-glycolide) nanoparticles for tumor-targeted drug delivery. Int J Pharm. 2016;509(1-2):483-491.

12. Phan QT, Le MH, Le TT, Tran TH, Xuan PN, Ha PT. Characteristics and cytotoxicity of folate-modified curcumin-loaded PLA-PEG micellar nano systems with various PLA:PEG ratios. Int $J$ Pharm. 2016; 507(1-2):32-40.

13. Tang H, Murphy CJ, Zhang B, et al. Curcumin polymers as anticancer conjugates. Biomaterials. 2010;31(27):7139-7149.

14. Mura S, Nicolas J, Couvreur P. Stimuli-responsive nanocarriers for drug delivery. Nat Mater. 2013;12(11):991-1003.

15. Cheng R, Meng F, Deng C, Zhong Z. Bioresponsive polymeric nanotherapeutics for targeted cancer chemotherapy. Nano Today. 2015; 10(5):656-670.

16. Toyokuni S, Okamoto K, Yodoi J, Hiai H. Persistent oxidative stress in cancer. FEBS Lett. 1995;358(1):1-3.

17. Lopez-Lazaro M. Dual role of hydrogen peroxide in cancer: possible relevance to cancer chemoprevention and therapy. Cancer Lett. 2007;252(1):1-8.

18. Circu ML, Aw TY. Reactive oxygen species, cellular redox systems, and apoptosis. Free Radic Biol Med. 2010;48(6):749-762.

19. Valko M, Leibfritz D, Moncol J, Cronin MT, Mazur M, Telser J. Free radicals and antioxidants in normal physiological functions and human disease. Int J Biochem Cell Biol. 2007;39(1):44-84.

20. Ganta S, Devalapally H, Shahiwala A, Amiji M. A review of stimuliresponsive nanocarriers for drug and gene delivery. J Control Release. 2008;126(3):187-204.

21. Li M, Li S, Chen H, et al. Preparation of conjugated polymer grafted with $\mathrm{H}_{2} \mathrm{O}_{2}$-sensitive prodrug for cell imaging and tumor cell killing. ACS Appl Mater Interfaces. 2016;8(1):42-46.
22. Zhang BF, Xing L, Cui PF, et al. Mitochondria apoptosis pathway synergistically activated by hierarchical targeted nanoparticles codelivering siRNA and lonidamine. Biomaterials. 2015;61:178-189.

23. Lawrence K, Flower SE, Kociok-Kohn G, Frost CG, James TD. A simple and effective colorimetric technique for the detection of boronic acids and their derivatives. Anal Methods. 2012;4(8):2215-2217.

24. Wang K, Zhang T, Liu L, et al. Novel micelle formulation of curcumin for enhancing antitumor activity and inhibiting colorectal cancer stem cells. Int J Nanomedicine. 2012;7:4487-4497.

25. Wang Q, Uzunoglu E, Wu Y, Libera M. Self-assembled poly (ethylene glycol)-co-acrylic acid microgels to inhibit bacterial colonization of synthetic surfaces. ACS Appl Mater Interfaces. 2012;4(5):2498-2506.

26. Letchford K, Liggins R, Burt H. Solubilization of hydrophobic drugs by methoxy poly (ethylene glycol)-block-polycaprolactone diblock copolymer micelles: theoretical and experimental data and correlations. J Pharm Sci. 2008;97(3):1179-1190.

27. Song C-C, Ji R, Du F-S, Liang D-H, Li Z-C. Oxidation-accelerated hydrolysis of the ortho ester-containing acid-labile polymers. ACS Macro Lett. 2013;2(3):273-277.

28. Vandita K, Shashi B, Santosh KG, Pal KI. Enhanced apoptotic effect of curcumin loaded solid lipid nanoparticles. Mol Pharm. 2012; 9(12):3411-3421

29. Wu C, Shi L, Li Q, et al. New strategy of efficient inhibition of cancer cells by carborane carboxylic acid-CdTe nanocomposites. Nanomedicine. 2012;8(6):860-869.

30. Wimmer MA, Goldbach HE. A miniaturized curcumin method for the determination of boron in solutions and biological samples. J Plant Nutr Soil Sci. 1999;162(1):15-18.

31. Mitra K, Gautam S, Kondaiah P, Chakravarty AR. The cisDiammineplatinum(II) complex of curcumin: a dual action DNA crosslinking and photochemotherapeutic agent. Angew Chem Int Ed Engl. 2015; 54(47):13989-13993.

32. Leung MHM, Colangelo H, Kee TW. Encapsulation of curcumin in cationic micelles suppresses alkaline hydrolysis. Langmuir. 2008;24(11): 5672-5675.

33. Leung MH, Pham DT, Lincoln SF, Kee TW. Femtosecond transient absorption spectroscopy of copper(II)-curcumin complexes. Phys Chem Chem Phys. 2012;14(39):13580-13587.

34. Maeda H, Wu J, Sawa T, Matsumura Y, Hori K. Tumor vascular permeability and the EPR effect in macromolecular therapeutics: a review. $J$ Control Release. 2000;65(1-2):271-284.

35. Lu B, Wang CF, Wu DQ, Li C, Zhang XZ, Zhuo RX. Chitosan based oligoamine polymers: synthesis, characterization, and gene delivery. J Control Release. 2009;137(1):54-62.

36. Rietscher R, Czaplewska JA, Majdanski TC, et al. Impact of PEG and PEG-b-PAGE modified PLGA on nanoparticle formation, protein loading and release. Int J Pharm. 2016;500(1-2):187-195.

37. Khemtong C, Kessinger CW, Gao JM. Polymeric nanomedicine for cancer MR imaging and drug delivery. Chem Commun. 2009;28(24): 3497-3510.

38. Su Z, Chen M, Xiao Y, et al. ROS-triggered and regenerating anticancer nanosystem: an effective strategy to subdue tumor's multidrug resistance. J Control Release. 2014;196:370-383.

39. Wang YJ, Pan MH, Cheng AL, et al. Stability of curcumin in buffer solutions and characterization of its degradation products. $J$ Pharm Biomed Anal. 1997;15(12):1867-1876.

40. Yallapu MM, Jaggi M, Chauhan SC. Beta-Cyclodextrin-curcumin selfassembly enhances curcumin delivery in prostate cancer cells. Colloids Surf B Biointerfaces. 2010;79(1):113-125.

41. Kunwar A, Barik A, Mishra B, Rathinasamy K, Pandey R, Priyadarsini KI. Quantitative cellular uptake, localization and cytotoxicity of curcumin in normal and tumor cells. Biochim Biophys Acta. 2008;1780(4): 673-679. 
International Journal of Nanomedicine

Dovepress

\section{Publish your work in this journal}

The International Journal of Nanomedicine is an international, peerreviewed journal focusing on the application of nanotechnology in diagnostics, therapeutics, and drug delivery systems throughout the biomedical field. This journal is indexed on PubMed Central, MedLine, CAS, SciSearch ${ }^{\circledR}$, Current Contents ${ }^{\circledR} /$ Clinical Medicine,
Journal Citation Reports/Science Edition, EMBase, Scopus and the Elsevier Bibliographic databases. The manuscript management system is completely online and includes a very quick and fair peer-review system, which is all easy to use. Visit http://www.dovepress.com/ testimonials.php to read real quotes from published authors.

Submit your manuscript here: http://www.dovepress.com/international-journal-of-nanomedicine-journal 